\title{
HIGH GROWTH DUMMERSTORF MICE HAVE REDUCED SPECIFIC FORCE OF SLOW AND FAST TWITCH SKELETAL MUSCLE
}

\author{
Petras Minderis ${ }^{1}$, Andrej Fokin ${ }^{1}$, Aivaras Ratkevičius ${ }^{1,2}$ \\ Lithuanian Sports University', Kaunas, Lithuania \\ University of Aberdeen ${ }^{2}$, Foresterhill, Scotland, UK
}

\begin{abstract}
Background. Mouse strains differ in body and skeletal muscle mass. It is commonly believed that specific force is a constant value irrespective of muscle mass. We hypothesised that excessive muscle hypertrophy might compromise force output.

Methods. We studied force generating capacity and muscle mass of isolated soleus (SOL) and extensor digitorum longus (EDL) muscles in 14-15-week-old males of C57BL/6J, BEH+/+ and DUH mice ( $n=7$ per strain). In addition, muscles of young (4-5 weeks old, $n=7$ per strain) BEH $+/+$ and DUH mice were also studied. Specific forces were calculated as isometric tetanic force divided by the estimated physiological cross-section area (PCSA) of the muscles.

Results. DUH strain generated lower specific force $(p<.01-.001)$ than both $\mathrm{C} 57 \mathrm{BL} / 6 \mathrm{~J}$ and $\mathrm{BEH}+/+$ strains in SOL (110 \pm 20 vs. $146 \pm 28$ and $164 \pm 8 \mathrm{mN} / \mathrm{mm}^{2}$, respectively) and EDL muscles (74 \pm 18 vs. $101 \pm 19$ and $95 \pm$ $11 \mathrm{mN} / \mathrm{mm}^{2}$, respectively). There were no differences between muscles of young and adult mice $(p>.05)$. C57BL/6J and $\mathrm{BEH}+/+$ generated similar specific force.

Conclusions. Our results show that body mass is not associated with reduction in specific force of skeletal muscles in mice. It seems that age did not affect specific force either. However, the heaviest DUH mice had lower specific force in both slow twitch SOL and fast twitch EDL compared to $\mathrm{BEH}+/+$ and $\mathrm{C} 57 \mathrm{BL} / 6 \mathrm{~J}$ mice. It appears that DUH strain could be a useful model in studying factors limiting specific force of skeletal muscle.
\end{abstract}

Keywords: muscle hypertrophy, muscles mass, specific force, mice.

\section{INTRODUCTION}

$\mathrm{S}$ keletal muscle is the most abundant tissue constituting $40-50 \%$ of body mass in vertebrates. Muscle function is positively associated with physical fitness and plays a critical role in health and well-being (Cohen, Nathan, \& Goldberg, 2015). Loss of muscle mass and function is observed in ageing, after musculoskeletal trauma as well as in various chronic diseases such as neuromuscular disorders, cancer, diabetes, sepsis and HIV (Cohen et al., 2015).

Muscle mass is to a large extent determined by genetic factors (Pescatello, Devaney, Hubal, Thompson, \& Hoffman, 2013). However, only few genes affecting muscle function are known. For instance, dysfunction of Mstn gene results in substantial hypertrophy of skeletal muscles in mice and humans (McPherron, Lawler, \& Lee, 1997; Schuelke et al., 2004). Identification of genes and physiological mechanisms that mediate their effects on skeletal muscles might help to develop new therapeutic strategies against various conditions associated with muscle dysfunction.

It is often assumed that muscle mass reflects muscle force generating capacity (Jones, Bishop, Woods, \& Green, 2008), but neurological factors may interfere with force production in humans as 
well (Degens, Erskine, \& Morse, 2009). Moreover, specific force or muscle force per physiological cross sectional area (PCSA) tends to be higher in type 2 than type 1 muscle fibres (Bottinelli, Schiaffino, \& Reggiani, 1991; Krivickas, Dorer, Ochala, \& Frontera, 2011; Stienen, Kiers, Bottinelli, \& Reggiani, 1996; Young, 1984). Little effort has been spent in search for other factors modulating specific force. Identification of inbred mouse strains that differ in specific force of isolated muscles excluding neurological influence could be an important initial step, which would facilitate search for the relevant genetic factors and physiological mechanisms.

It has been established that $\mathrm{C} 57 \mathrm{BL} / 6 \mathrm{~J}$, Berlin high $(\mathrm{BEH}+/+)$ and Dummerstorf high (DUH) strains of mice differ significantly in body and muscle mass (Amthor et al., 2007; Lionikas et al., 2013a). It is often speculated that an increase in pennation angles of muscle fibres can reduce specific force in skeletal muscles showing excessive hypertrophy (Amthor et al., 2007). The main aim of this study was to test the hypothesis that specific muscle strength decreases with increase in muscle mass. We compared specific force in extensor digitorum longus (EDL) and soleus (SOL) muscles in $\mathrm{C} 57 \mathrm{BL} / 6 \mathrm{~J}, \mathrm{BEH}+/+$ and DUH strains. Skeletal muscles undergo significant growth from young age to adulthood (Agbulut, Noirez, Beaumont, \& Butler-Browne, 2003; Gokhin, Ward, Bremner, \& Lieber, 2008). Thus we studied skeletal muscles of adult and young mice before they reach adult body and muscle size. This allowed discriminating between effects of mouse strain and mass size of specific muscle force.

\section{METHODS}

Animals. All procedures involving mice were approved by the Lithuanian State Food and Veterinary Service (No. 0223 in 2012). All mice were housed in standard cages under the same environmental conditions (12:12 h light-dark cycle at $21-23^{\circ} \mathrm{C}$ ) with ad libitum access to food and water. 14-15 week-old males of C57BL/6J, BEH+/+ and DUH strains were studied. In addition, muscles of young mice (4-5 weeks old) of both large growth strains $(\mathrm{BEH}+/+$ and $\mathrm{DUH})$ strains were also studied in order to examine strain effects on muscle force before the onset of muscle growth. $\mathrm{BEH}+/+$ mice was generated by crossing BEH mice which have dysfunctional Mstn gene with the Berlin Low
(BEL) strain and then repeatedly backcrossing the offspring to BEH using marker assisted selection for the wild type allele $(+)$ myostatin (Amthor et al., 2007; Lionikas et al., 2013b). Therefore, BEH+/+ mice have normally functioning myostatin as both C57BL/6J and DUH. Animal number in each group was the same $(n=7)$.

Muscle properties. Mice were euthanized by cervical dislocation and SOL or EDL was excised with 5-0 silk suture tied securely to the proximal and distal tendons. The muscle was then fixed between two platinum plate electrodes in $100 \mathrm{ml}$ Radnoti tissue bath filled with the Tyrode solution (in mM: $121 \mathrm{NaCl}, 5 \mathrm{KCl}, 0.5 \mathrm{MgCl}_{2}, 1.8 \mathrm{CaCl}_{2}, 0.4$ $\mathrm{NaH}_{2} \mathrm{PO}_{4}, 0.1 \mathrm{NaEDTA}, 24 \mathrm{NaHCO}_{3}, 5.5$ glucose) that was bubbled with a gas mixture of $95 \% \mathrm{O}_{2}$ and $5 \% \mathrm{CO}_{2}$ at $\mathrm{pH}$ 7.4. The bath was maintained at room temperature of $\sim 22-25^{\circ} \mathrm{C}$ during all experiments. The muscle was suspended vertically in the bath with the proximal tendon attached securely to the lever arm of muscle test system (1200A-LR Muscle Test System, Aurora Scientific Inc., Canada) and distal tendon to an iron hook. Muscle length was increased in steps every $30 \mathrm{~s}$ just after delivery of electrical pulse to evoke a twitch contraction. This procedure was continued until twitch force did not increase with the increase in muscle length. The muscle was then photographed with the length scale in the background to assess muscle length with a precision of $0.1 \mathrm{~mm}$. The muscle was kept at this optimal length $\left(\mathrm{L}_{0}\right)$ during the assessment of contractile properties. Firstly, single twitch was generated and peak twitch force was measured. Twitch contraction time was assessed as the time from the beginning of the contraction to the peak of twitch force. Twitch half relaxation time was measured as the time taken for force to decline from peak to $50 \%$ of peak value. Afterwards, the muscle was subjected to $300 \mathrm{~ms}$ (EDL) and $900 \mathrm{~ms}$ (SOL) trains of stimuli at 25, 50, 75, 100, 150 and $200 \mathrm{~Hz}$ for assessment of peak tetanic force and force-frequency relationship. Specific tetanic force was calculated as peak tetanic force divided by muscle physiological cross-sectional area (PCSA). PCSA was estimated by dividing muscle wet weight by the product of fibre length $\left(\mathrm{L}_{\mathrm{f}}\right)$, and the density of mammalian skeletal muscle $\left(1.06 \mathrm{~g} / \mathrm{cm}^{3}\right)$ as described previously (Brooks \& Faulkner, 1988). $\mathrm{L}_{\mathrm{f}} / \mathrm{L}_{0}$ ratios of 0.45 and 0.70 were used in these calculations for adult mice EDL and SOL respectively, and $\mathrm{L}_{\mathrm{f}} / \mathrm{L}_{0}$ ratios of 0.45 and 0.71 were used for young mice EDL and SOL respectively 
(Brooks \& Faulkner, 1988). The muscle was freed from tendons, blotted and weighed (Kern, ABS 80-4, Germany) following all the measurements.

Statistical analysis. All analyses were performed using SPSS 20.0 package for Windows. The Shapiro-Wilk test was used to determine the normality of the variables in the strains. Differences between strains were assessed by oneway ANOVA test. LSD test was applied for post hoc comparisons. For all statistical tests, the level of significance was set a priori at $p<.05$. All data are presented as means $\pm S D$.

\section{RESULTS}

Mice body and skeletal muscle morphometric properties are presented in Table. Adult animals of all three strains were significantly different in all these parameters $(p<.05-.001)$. DUH strain was heaviest and had largest muscles compared to other two strains $(p<.001)$. $\mathrm{BEH}+/+$ mice were intermediate by these parameters between C57BL/6J and DUH. Muscle contribution to the overall body mass differed between these strains. C57BL/6J mice had larger $(p<.05-.001)$ ratios of muscle to body weight than $\mathrm{BEH}+/+$ and DUH, especially for SOL. According to this parameter, muscle contribution to body weight was smallest in $\mathrm{BEH}+/+$ mice while DUH strain showed intermediate values between $\mathrm{BEH}+/+$ and C57BL/6J strains. Other morphometric parameters such as muscle and fibre length as well as PCSA were associated with the body size as mice differed significantly in body mass. Young mice of both larger strains $(\mathrm{BEH}+/+$ and $\mathrm{DUH})$ were selected by body weight to match the $\mathrm{C} 57 \mathrm{BL} / 6 \mathrm{~J}$ strain. They did not differ in this parameter, but the rest morphometric parameters like weight and PCSA of muscles were lower $(p<.05-.001)$ compared to C57BL/6J strain.

Table. Morphometric properties of soleus (SOL) and extensor digitorum longus (EDL) muscle in C57BL/6J, BEH+/+ and DUH strains of mice

\begin{tabular}{|c|c|c|c|c|c|}
\hline & \multicolumn{2}{|c|}{ Young } & \multicolumn{3}{|c|}{ Adult } \\
\hline & ВEH+/+ & DUH & C57BL/6J & ВEH+/+ & DUH \\
\hline \multicolumn{6}{|c|}{ SOL properties } \\
\hline BW (g) & $25.0 \pm 1.9^{* * *}$ & $27.1 \pm 2.3^{* * *}$ & $26.4 \pm 0.7$ & $51.8 \pm 4.0^{\dagger \dagger}$ & $77.6 \pm 9.2^{1+t+*}$ \\
\hline MW (mg) & $6.1 \pm 0.6^{* * *+\dagger \dagger}$ & $7.5 \pm 0.9^{* * *+\dagger}$ & $10.5 \pm 0.9$ & $13.5 \pm 1.1^{\dagger \dagger}$ & $25.0 \pm 3.6^{1+1+t+}$ \\
\hline MW/BW (\%) & $0.024 \pm 0.002^{\dagger \dagger \dagger}$ & $0.027 \pm 0.003^{* *+\dagger \dagger}$ & $0.040 \pm 0.004$ & $0.026 \pm 0.003^{\dagger \dagger \dagger}$ & $0.032 \pm 0.003^{1+t+4+}$ \\
\hline $\mathbf{L}_{0}(\mathbf{m m})$ & $11.3 \pm 0.7^{* * *+\dagger \dagger}$ & $10.9 \pm 0.6^{* * *+\dagger \dagger}$ & $13.0 \pm 0.7$ & $14.3 \pm 0.4^{\dagger \dagger}$ & $15.1 \pm 0.4^{\dagger \dagger \dagger}$ \\
\hline $\mathbf{L}_{\mathrm{f}}(\mathbf{m m})$ & $8.0 \pm 0.5^{* * *+\dagger \dagger}$ & $7.8 \pm 0.5^{* * *+\dagger \dagger}$ & $9.1 \pm 0.5$ & $10.0 \pm 0.3^{\dagger \dagger}$ & $10.6 \pm 0.3^{\dagger+t}$ \\
\hline $\operatorname{PCSA}\left(\mathrm{mm}^{2}\right)$ & $0.71 \pm 0.06^{* * *+\dagger \dagger}$ & $0.90 \pm 0.08^{* * * * \# \#}$ & $1.10 \pm 0.11$ & $1.31 \pm 0.12^{\dagger}$ & $2.23 \pm 0.29^{+1+t+4}$ \\
\hline \multicolumn{6}{|c|}{ EDL properties } \\
\hline BW (g) & $25.2 \pm 1.8^{* * *}$ & $25.7 \pm 0.9^{* * *}$ & $25.8 \pm 1.5$ & $49.1 \pm 3.7^{\dagger \dagger}$ & $80.5 \pm 6.2^{1+1+t+}$ \\
\hline MW (mg) & $9.0 \pm 0.4^{* * * \dagger}$ & $9.4 \pm 0.6^{* * *+}$ & $10.7 \pm 0.5$ & $14.7 \pm 1.0^{\dagger \dagger}$ & $30.7 \pm 2.4^{1+1+4 t}$ \\
\hline MW/BW (\%) & $0.037 \pm 0.00^{* * *+1 \dagger}$ & $0.036 \pm 0.003^{\dagger \dagger}$ & $0.042 \pm 0.003$ & $0.030 \pm 0.002^{\dagger \dagger}$ & $0.038 \pm 0.003$ \\
\hline $\mathbf{L}_{0}(\mathbf{m m})$ & $13.6 \pm 0.8$ & $13.4 \pm 0.7^{* * *}$ & $13.3 \pm 0.5$ & $14.2 \pm 0.8^{\dagger}$ & $16.9 \pm 0.7^{\dagger+1+t+}$ \\
\hline $\mathbf{L}_{\mathrm{f}}(\mathbf{m m})$ & $6.1 \pm 0.4$ & $6.0 \pm 0.3^{* * *}$ & $6.0 \pm 0.2$ & $6.4 \pm 0.3^{\dagger}$ & $7.6 \pm 0.3^{\mathrm{c} \uparrow+1+}$ \\
\hline $\operatorname{PCSA}\left(\mathrm{mm}^{2}\right)$ & $1.39 \pm 0.12^{* * *+\dagger}$ & $1.48 \pm 0.13^{* * * \dagger}$ & $1.69 \pm 0.13$ & $2.17 \pm 0.17^{+1+}$ & $3.81 \pm 0.38^{1+1+4+}$ \\
\hline
\end{tabular}

Note. Values are means $\pm S D$; BW, body weight; $\mathrm{MW}$, muscle weight; $\mathrm{MW} / \mathrm{BW}$, muscle weight to body weight ratio; $\mathrm{L}_{0}$, optimal muscle length; $\mathrm{L}_{\mathrm{f}}$, optimal fibre length; PCSA, physiological muscle cross-sectional area. ${ }^{* *} p<.01,{ }^{* * *} p<.001$ vs. adult mice of the same strain; ${ }^{\dagger} p<.05$, ${ }^{\dagger \dagger} p<$ $.01,{ }^{\dagger \dagger} p<.001$ vs. C57BL/6J, ${ }^{\star} p<.05,{ }^{* t} p<.001$ vs. BEH $+/+;{ }^{\#} p<.05$ vs. young BEH $+/+$. 


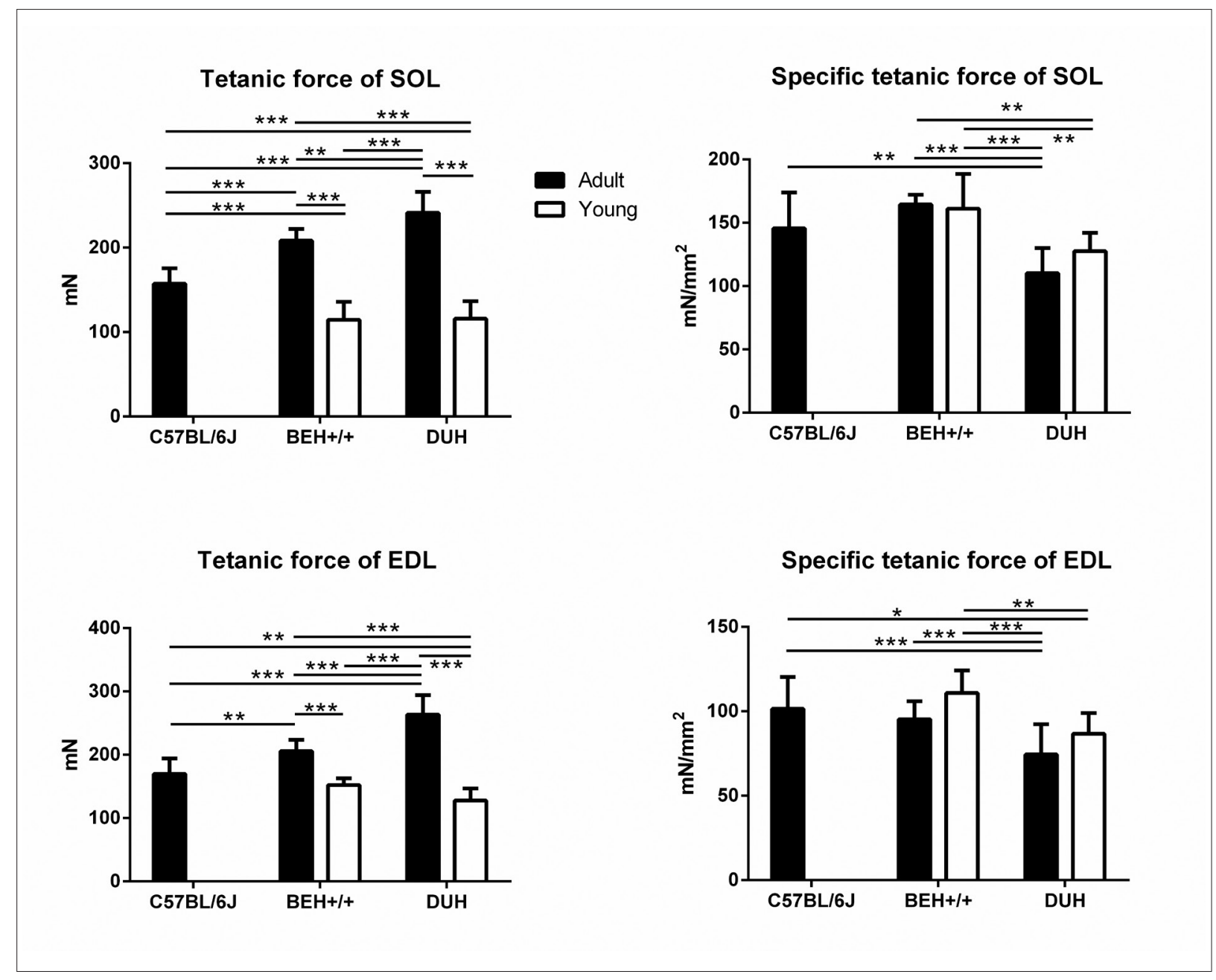

Figure 1. Tetanic force generation capacity of soleus (SOL) and extensor digitorum longus (EDL) muscles for C57BL/6J, BEH+/+ and DUH strains

Note. Values are means $\pm S D .{ }^{*} p<.05,{ }^{* *} p<.01,{ }^{* * *} p<.001$, respectively.

Data on contractile properties of the skeletal muscle are presented in Figure 1. The positive relationship between skeletal muscle size and their peak tetanic force was observed so that muscles of larger strains were stronger. Thus, SOL and EDL muscles of DUH mice were strongest $(p<.01-.001)$ than muscles of both $\mathrm{BEH}+/+$ and $\mathrm{C} 57 \mathrm{BL} / 6 \mathrm{~J}$ mice, and SOL and EDL muscles of $\mathrm{BEH}+/+$ mice were stronger $(p<.01-.001)$ than muscles of $\mathrm{C} 57 \mathrm{BL} / 6 \mathrm{~J}$ mice. However, there were differences between the strains when peak tetanic force was normalized to PCSA in order to calculate specific tetanic force. DUH strain had lowest $(p<.01-.001)$ specific tetanic force for both SOL and EDL compared to other two strains. Young DUH mice also showed lower specific force $(p<.05-.01)$ than the other strains for the both muscles. There were differences neither between $\mathrm{C} 57 \mathrm{BL} / 6 \mathrm{~J}$ and $\mathrm{BEH}+/+$ strains nor between young and adult mice of the same strain. The tendency toward increments of this parameter in young vs. adult mice was observed.

We have also assessed twitch speed as twitch contraction time and half relaxation time (Figure 2). Contraction time and half relaxation time of SOL and EDL muscles did not differ significantly between adult strains. Twitch speed, especially when assessed by half relaxation time, tended to be increased in young mice compared to adult mice. This was the most apparent on in young DUH mice which differed $(p<.05-.001)$ from the other strains in these properties. 


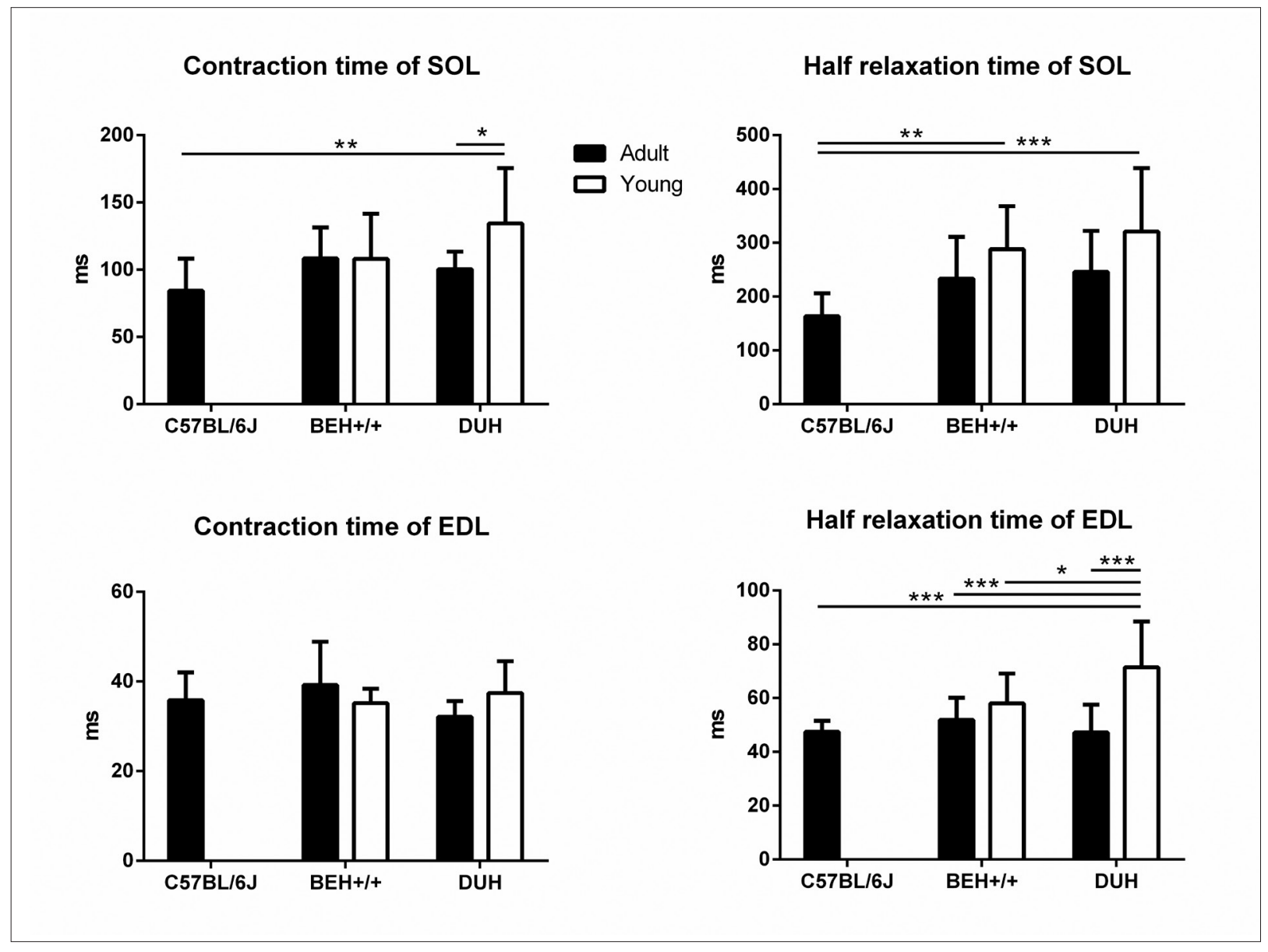

Figure 2. Twitch velocities of soleus (SOL) and extensor digitorum longus (EDL) muscles for C57BL/6J, BEH+/+ and DUH strains Note. Values are means $\pm S D .{ }^{*} p<.05,{ }^{* *} p<.01,{ }^{* * *} p<.001$, respectively.

\section{DISCUSSION}

The main aim of the study was to test the hypothesis that increase in body and muscle mass is associated with reduction in specific force of skeletal muscles in mice. The results of the study do not agree with this hypothesis. C57BL/6J and $\mathrm{BEH}+/+$ mice did not differ in specific force of SOL or EDL despite two-fold differences in body mass. Specific muscle force was also similar in young and adult mice which differed several fold in body mass. Interestingly, however, the heaviest DUH mice had reduced specific force in both SOL an EDL.

We studied C57BL/6J mice which had similar body mass as many other inbred strains (Reed, Bachmanov, \& Tordoff, 2007) and compared this strain with two high growth strains, i.e. $\mathrm{BEH}+/+$ and DUH strains. The BEH+/+ and DUH strains were generated by selection for muscularity and/or body weight score over more than 30 generations (Bünger et al., 2004). These strains were referred to as strains with large protein accretion and thus with large muscle mass (Varga et al., 1997; Bünger et al., 2004). Muscle of BEH strain is associated with the Compact mutation in the Mstn gene which contributes to doubling mass of most muscles (Varga et al., 1997; Amthor et al., 2007; Minderis et al., 2015). Myostatin factor was eliminated in this study as $\mathrm{BEH}+/+$ mice with the wild type allele were examined. This was done to eliminate specific effects of myostatin gene which has been associated with low specific force in mice (Minderis et al., 2015). Interestingly, however, muscle mass to body mass ratio of both $\mathrm{BEH}+/+$ and DUH was lower than in C57BL/6J mice. Thus, enlargement of tissues other than skeletal muscles is probably of major importance in determining body mass of $\mathrm{BEH}+/+$ and DUH mice.

We did not find any differences in specific force between young and adult mice. Our hypothesis 
was that adult mice would show lower specific force than young mice. Muscle hypertrophy leads to a decrease in specific force if it associated with dramatic increase in muscle fibres diameter without increase in attachment area for muscle fibres at the myotendinous junction (Degens, 2012). Mice undergo significant increase in muscle mass in the process of maturation. It could be that this is matched by an increase in attachment area for muscle fibres so that pennation angles of muscle fibres do not change significantly in spite of dramatic changes in muscle mass. These assumptions are supported by in vivo human studies which show that maturation has no effect on architecture of muscle fibres (Morse et al., 2008; O'Brien, Reeves, Baltzopoulos, Jones, \& Maganaris, 2010). In addition, prepubertal children and adults have the same specific force of quadriceps (O'Brien et al., 2010). Interestingly, however, specific force of gastrocnemius was higher by $21 \%$ in pubescent boys compared to adult men (Morse et al., 2008). This was not due to changes in moment arm length, muscle architecture or antagonist coactivation and the authors attributed these findings to possible discrepancies in measuring PCSA between boys and men. In our case, however, there might be genetic differences in muscle architecture between the mouse stains. These genetic effects could explain low specific force in DUH mice as muscle fibre pennation angle is an important determinant of muscle force output (Ikegawa et al., 2008; Kawakami, Abe, Kuno, \& Fukunaga, 1995).

In addition to body and skeletal muscle mass, muscle fibre-type composition is also determined by genetic factors. Lionikas et al. (2013 a) showed that distinct strains differing in muscle mass also differ in muscle fibre-type composition. DUH mice have twice as many type 1 fibres than C57BL/6 J $(64 \pm 11$ vs. $31 \pm 2 \%)$ in SOL while BEH mice with the homozygous Compact allele in Mstn gene had $35 \pm 2 \%$ type 1 fibres (Lionikas et al., 2013a). A constitutive myostatin knock out results in an approximately $20 \%$ increase in the relative content of type 2 fibres at the expense of type 1 fibres in SOL (Girgenrath, Song, \& Whittemore, 2005). Thus it is likely that $\mathrm{BEH}+/+$ mice with wild type myostatin might be intermediate by proportion of type 1 fibres between C57BL/6J and DUH mice. Twitch speed measurements, especially half relaxation time, suggest that SOL of $\mathrm{C} 57 \mathrm{BL} / 6 \mathrm{~J}$ is faster than in the other two strains. This might suggest that lower specific force in DUH is somehow associated with greater amount of slow type 1 fibres (Bottinelli et al., 1991; Krivickas et al., 2011; Stienen et al., 1996; Young, 1984). However, this explanation can hardly be valid for EDL which contains only negligible quantities of type 1 fibres.

It is also possible that contractile protein levels are lower in DUH mice compared to $\mathrm{BEH}+/+$ and C57BL/6J mice. The average myonuclear domain (MND) is larger in myostatin-deficient mice which show excessive muscle hypertrophy compared to wild type mice (Qaisar et al., 2012). Muscle fibres with large MNDs show lower levels of contractile proteins (Qaisar et al., 2012). MND is not fixed and can increase in response to growth stimulus (Van der Meer, Jaspers, \& Degens, 2011). Qaisar et al. (2012) have also proposed a hypothesis about a size threshold for MND beyond which muscle fibres are not able to maintain adequate myofibrillar protein levels and number of functioning cross-bridges. According to Lionikas et al. (2013a) DUH mice has a larger CSA of both type 1 and 2A fibres than C57BL/6J strain in SOL and larger CSA of type $2 \mathrm{~A}$ but not type 1 fibres in SOL than myostatindeficient BEH which demonstrates lower specific force. As isoforms of type 2 fibres are in both SOL (2A) and EDL (2B, $2 \mathrm{X}$ and very few $2 \mathrm{~A}$ ) muscles in considerable amounts they could be as a potential candidate for lower specific force due to enlarged MNDs in type 2 fibres. The drawback of this theory is that it cannot explain why young DUH mice with 3-fold smaller muscle mass (i.e. significantly smaller muscle fibres) and therefore supposedly smaller MNDs compared to adult counterparts have lower specific force as well.

One might argue that it is not reliable to compare skeletal muscle function between muscles of young mice with ongoing developmental hypertrophy and mature muscles of adult mice. We did not find any studies where force generation capacity was compared between young and adult mice of DUH and BEH $+/+$ strains. However, 2-3 month old $\mathrm{C} 57 \mathrm{BL} / 6 \mathrm{~J}$ mice did not differ from 9-10 month mice in specific force of SOL and EDL (Brooks \& Faulkner, 1988). Approximately 2 -fold and 3-fold increase in skeletal muscle mass was observed in the $\mathrm{BEH}+/+$ and DUH strains from the age of 4-5 weeks to $14-15$ weeks in our study. Several studies show that skeletal muscles of $\sim 1$ month old mice are already displaying all characteristics typical for mature muscle (Agbulut et al., 2003, Gokhin et al., 2008). During the first days after birth skeletal muscles of mice have lower 
density of contractile material and show different fibre type composition, but then catch up with adult muscle within several weeks. Following a period of 21 days after birth SOL and EDL muscles display a sequential transition from embryonic to neonatal and eventually to adult myosin heavy chain (MyHC) isoforms though few differences in a proportion of adult MyHC isoforms in muscles was still remaining after 21 days (Agbulut et al., 2003). Gokhin et al. (2008) demonstrated a robust increase in a myofibrillar packing from 48 to $93 \%$ in mice tibialis anterior muscle fibres with an accompanying increase in maximum isometric tension to a 6 -fold following a period of 28 days postnatal. Collectively, this evidence suggests that young mice of 28-35 days as in our study should demonstrate a force generation capacity comparable to adult mice. Small differences in contraction time and half relaxation time between young and adult mice herein might be associated with still unfinished transition processes in composition of MyHC isoforms.

There are also methodological issues to consider when assessing specific force. Some investigators calculate muscle force relative to a muscle mass while others normalize force to muscle CSA. The calculations of specific force by dividing the absolute force with muscle mass are common in studies where muscle lengths are similar between the animal groups. In our case, however, there were significant differences in muscle length between strains and age groups. It appears that differences in muscle length have to be accounted when comparing muscles mass of mice in our study. This involved calculation of muscle CSA. There are two different methods for assessment of muscle CSA. Some investigators calculate an anatomical CSA (ACSA) while others estimate the physiological CSA (PCSA). It appears that PCSA provides a better reflection of muscle force generating capacity since skeletal muscles differ in the length of muscle fibres as the ratio of fibre to muscle length $\left(\mathrm{L}_{\mathrm{f}} / \mathrm{L}_{0}\right)$ is 0.70 and 0.45 for SOL and EDL of C57BL/6J mice, respectively (Brooks \& Faulkner, 1988). We used these ratios to evaluate a fibre length indirectly for a PCSA calculation in all three strains as we were not able to find any information about fibre to muscle length ratios for $\mathrm{BEH}+/+$ and $\mathrm{DUH}$ mice. Thus, an applied ratio if it is inaccurate might result in an underestimation or overestimation of a real PCSA of these strains. However, we suppose that if there are any differences in a fibre to muscle ratio between C57BL/6J and larger strains it should not be dramatic. Indeed, in SOL muscle of the ICR mice strain weighing 40-50 g (very similar to the $\mathrm{BEH}+/+$ mice) showed $\mathrm{L}_{\mathrm{f}} / \mathrm{L}_{0}$ ratio of 0.71 (Choi \& Widrick, 2009; Widrick \& Barker, 2006). EDL muscles of WI/HicksCar rats, which are significantly larger animals than mice, showed $\mathrm{L}_{\mathrm{f}} /$ $\mathrm{L}_{0}$ ratio of 0.4 which is also similar to $\mathrm{C} 57 \mathrm{BL} / 6 \mathrm{~J}$ mice (Carlson \& Faulkner, 1998).

Another methodological issue may concern viability of muscles differing in size during an ex vivo procedure. As muscles of the DUH strain are much thicker it might be argued that deeper fibres of these muscles are affected by hypoxia. Segal and Faulkner (1985) demonstrated that ex vivo SOL and EDL ( $70-90 \mathrm{mg})$ of rats show good contractile performance over significant periods of time when incubated as in our experiment using temperatures not exceeding $25{ }^{\circ} \mathrm{C}$. Moreover, such temperature ensures an adequate $\mathrm{O}_{2}$ diffusion and similar to fresh muscles glycogen content.

\section{CONCLUSIONS}

Results of the study do not agree with the hypothesis that increase in body mass is associated with reduction in specific force of skeletal muscles in mice. Interestingly, however, the heaviest DUH mice had reduced specific force in both SOL an EDL. It appears that this mouse strain could be an interesting model in studying factors limiting specific muscle force.

Acknowledgements. We wish to thank Mrs Indre Libnickienè for her excellent technical assistance provided during the project.

\section{REFERENCES}

Agbulut, O., Noirez, P., Beaumont, F., \& ButlerBrowne, G. (2003). Myosin heavy chain isoforms in postnatal muscle development of mice. Biology of the Cell, 95(6), 399-406. doi: 10.1016/S0248-4900(03)00087-X
Amthor, H., Macharia, R., Navarrete, R., Schuelke, M., Brown, S. C., Otto, A., ... \& Patel, K. (2007). Lack of myostatin results in excessive muscle growth but impaired force generation. Proceedings of the National 
Academy of Sciences of the United States of America, 104(6), 1835-1840. doi: 10.1073/pnas.0604893104

Bottinelli, R., Schiaffino, S., \& Reggiani, C. (1991). Force-velocity relations and myosin heavy chain isoform compositions of skinned fibres from rat skeletal muscle. The Journal of Physiology, 437, 655-672. doi: 10.1113/ jphysiol.1991.sp018617

Brooks, S. V., \& Faulkner, J. A. (1988). Contractile properties of skeletal muscles from young, adult and aged mice. The Journal of Physiology, 404, 71-82. doi: 10.1113/jphysiol.1988.sp017279

Bünger, L., Ott, G., Varga, L., Schlote, W., Rehfeldt, C., Renne, U., ... \& Hill, W. G. (2004). Marker assisted introgression of the Compact mutant myostatin allele: MstnCmpt-dllAbc into a mouse line with extreme growth - effects on body composition and muscularity. Genetics Research, 84(3), 161-173.

Carlson, B. M., \& Faulkner, J. A. (1988). Reinnervation of long-term denervated rat muscle freely grafted into an innervated limb. Experimental Neurology, 102(1), 50-56. doi: 10.1016/0014-4886(88)90077-5

Choi, S. J., \& Widrick, J. J. (2009). Combined effects of fatigue and eccentric damage on muscle power. Journal of Applied Physiology, 107(4), 1156-1164. doi: 10.1152/ japplphysiol.00403.2009

Cohen, S., Nathan, J. A., \& Goldberg, A. L. (2015). Muscle wasting in disease: Molecular mechanisms and promising therapies. Nature Reviews Drug Discovery, 14(1), 58-74. doi: 10.1038/nrd4467.

Degens, H., Erskine, R. M., \& Morse, C. I. (2009). Disproportionate changes in skeletal muscle strength and size with resistance training and ageing. Journal of Musculoskeletal and Neuronal Interactions, 9(3), 123129.

Degens, H. (2012). Determinants of Skeletal Muscle Hypertrophy and the Attenuated Hypertrophic Response at Old Age. Journal of Sports Medicine \& Doping Studies, S1:003, 2-9. doi: 10.4172/2161-0673.S1-003

Girgenrath, S., Song, K., \& Whittemore, L. A. (2005). Loss of myostatin expression alters fiber-type distribution and expression of myosin heavy chain isoforms in slowand fast-type skeletal muscle. Muscle \& Nerve, 31(1), 34-40.

Gokhin, D. S., Ward, S. R., Bremner, S. N., \& Lieber, R. L. (2008). Quantitative analysis of neonatal skeletal muscle functional improvement in the mouse. Journal of Experimental Biology, 211(Pt 6), 837-843. doi: $10.1242 /$ jeb.014340.

Ikegawa, S., Funato, K., Tsunoda, N., Kanehisa, H., Fukunaga, T., \& Kawakami, Y. (2008). Muscle force per cross-sectional area is inversely with pennation angle in strength trained athletes. The Journal of Strength and Conditioning Research, 22(1), 128-131. doi: 10.1519/ JSC.0b013e31815f2fd3

Jones, E. J., Bishop, P. A., Woods, A. K., \& Green J. M. (2008). Cross-sectional area and muscular strength: A brief review. Sports Medicine, 38(12), 987-994. doi: 10.2165/00007256-200838120-00003

Kawakami, Y., Abe, T., Kuno, S. Y., \& Fukunaga, T. (1995). Training-induced changes in muscle architecture and specific tension. European Journal of Applied Physiology and Occupational Physiology, 72(1-2), 37-43.

Krivickas, L. S., Dorer, D. J., Ochala, J., \& Frontera, W. R. (2011). Relationship between force and size in human single muscle fibres. Experimental Physiology, 96(5), 539-547. doi: 10.1113/expphysiol.2010.055269

Lionikas, A., Kilikevicius, A., Bünger, L., Meharg, C., Carroll, A. M., Ratkevicius, A., ... \& Blizard, D. A. (2013b). Genetic and genomic analyses of musculoskeletal differences between BEH and BEL strains. Physiological Genomics, 45(20), 940-947. doi: 10.1152/physiolgenomics.00109.2013

Lionikas, A., Smith, C. J., Smith, T. L., Bünger, L., Banks, R. W., \& Bewick, G. S. (2013a). Analyses of muscle spindles in the soleus of six inbred mouse strains. Journal of Anatomy, 223(3), 289-296. doi: 10.1111/ joa. 12076

McPherron, A. C., Lawler, A. M., \& Lee, S. J. (1997). Regulation of skeletal muscle mass in mice by a new TGF-beta superfamily member. Nature, 387(6628), 8390. doi:10.1038/387083a0

Minderis, P., Kilikevicius, A., Baltusnikas, J., Alhindi, Y., Venckunas, T., Bunger, L., ... \& Ratkevicius, A. (2015). Myostatin dysfunction is associated with reduction in overload induced hypertrophy of soleus muscle in mice. Scandinavian Journal of Medicine \& Science in Sports, Aug 24. doi: 10.1111/sms.12532 [Epub ahead of print]

Morse, C. I., Tolfrey, K., Thom, J. M., Vassilopoulos, V., Maganaris, C. N., \& Narici, M. V. (2008). Gastrocnemius muscle specific force in boys and men. Journal of Applied Physiology, 104(2), 469-474. doi: 10.1152/ japplphysiol.00697.2007

O'Brien, T. D., Reeves, N. D., Baltzopoulos, V., Jones, D. A., \& Maganaris, C. N. (2010). In vivo measurements of muscle specific tension in adults and children. Experimental Physiology, 95(1), 202-210. doi: 10.1113/expphysiol.2009.048967

Pescatello, L. S., Devaney, J. M., Hubal, M. J., Thompson, P. D., \& Hoffman, E. P. (2013). Highlights from the functional single nucleotide polymorphisms associated with human muscle size and strength or FAMuSS study. Biomed Research International, article ID 643575, 11 pages. doi: 10.1155/2013/643575

Qaisar, R., Renaud, G., Morine, K., Barton, E. R., Sweeney, H. L., \& Larsson, L. (2012). Is functional hypertrophy and specific force coupled with the addition of myonuclei at the single muscle fiber level? The FASEB Journal, 26(3), 1077-1085. doi: 10.1096/fj.11-192195

Reed, D. R, Bachmanov, A. A, \& Tordoff, M. G. (2007). Forty mouse strain survey of body composition. Physiology \& Behavior, 91(5), 593-600. doi: 10.1016/j. physbeh.2007.03.026 
Schuelke, M., Wagner, K. R., Stolz, L. E., Hübner, C., Riebel, T., Kömen, ... \& Lee, S. J. (2004). Myostatin mutation associated with gross muscle hypertrophy in a child. The New England Journal of Medicine, 350(26), 2682-2688. doi: 10.1056/NEJMoa040933

Segal, S. S., \& Faulkner, J. A. (1985). Temperaturedependent physiological stability of rat skeletal muscle in vitro. American Journal of Physiology - Cell Physiology, 248(3 Pt 1), 265-270.

Stienen, G. J., Kiers, J. L., Bottinelli, R., \& Reggiani, C. (1996). Myofibrillar ATPase activity in skinned human skeletal muscle fibres: Fibre type and temperature dependence. The Journal of Physiology, 493(Pt 2), 299307. doi: 10.1113/jphysiol.1996.sp021384
Van der Meer, S. F., Jaspers, R. T., \& Degens, H. (2011). Is the myonuclear domain size fixed? Journal of Musculoskeletal and Neuronal Interactions, 11(4), 286-297.

Varga, L., Szabó, G., Darvasi, A., Müller, G., Sass, M., \& Soller, M. (1997). Inheritance and mapping of Compact (Cmpt), a new mutation causing hypermuscularity in mice. Genetics, 147(2), 755-764.

Widrick, J. J., \& Barker, T. (2006). Peak power of muscles injured by lengthening contractions. Muscle \& Nerve, 34(4), 470-477.

Young, A. (1984). The relative isometric strength of type I and type II muscle fibres in the human quadriceps. Clinical Physiology, 4(1), 23-32. doi: 10.1111/j.1475097X.1984.tb00641.x 